\title{
Analysis of a grinding efficiency in the electromagnetic mill for variable process and feed parameters
}

\author{
Marta Wołosiewicz-Głąb ${ }^{1, *}$, Dariusz Foszcz ${ }^{1}$, Daniel Saramak ${ }^{1}$, Tomasz Gawenda ${ }^{1}$, and Damian Krawczykowski ${ }^{1}$ \\ ${ }^{1}$ AGH University of Science and Technology, Faculty of Mining and Geoengineering, Department of Environmental Engineering \\ and Mineral Processing, Mickiewicza 30 Av., 30-059 Krakow, Poland
}

\begin{abstract}
Article describes issues related to the assessment of raw materials grinding efficiency in an electromagnetic mill. Application of such type of mill in grinding processes can result in measurable benefits of more efficient raw material grinding by reducing time needed to produce a product of a suitable particle size compared to conventional mills. The expected effect of application of a system based on an electromagnetic mill is to achieve a lower energy consumption of grinding process for raw material processing compared to the existing equipment used for the fine grinding. A key element of correct design of comminution circuits in processing of particular feed mineral is to identify the impact of key factors affecting the efficiency of the grinding process. The most important factors determining the efficiency of the grinding process are the time, the construction parameters of the machine, the type of grinding media used in grinding process, as well as the parameters of the feed, among others the crushing resistance or particle size. The paper presents the results of kinetic study of copper ore grinding in electromagnetic mill for variable feed particle size distribution of and different sizes of grinding media.
\end{abstract}

\section{Introduction}

Fine grinding operations are part of processing in case of many mineral raw materials. Depending on the required particle size distribution and maximum grain size of final product, grinding process is conducted in appropriate types of mills. Such devices work with different efficiency, determined by the energy consumption, performance and especially comminution degree of the final product. In ores processing, the required particle size is primarily conditioned by mineral particle size, the applied beneficiation technology and the grinding costs. Due to constant decrease of useful component content in the currently used ores, in order to obtain a comparable amount of metal in the concentrate, manufacturers are striving to increase production which means an increase in operating costs. Such situation stimulates further research on technical and technological solutions enabling the process of ore treatment to be run at the lowest possible cost. Due to the fact that comminution processes account for about $50-60 \%$ of operating costs, the main efforts are directed to these operations, and since the finer is a comminution product, the more energy has to be delivered, and the newer comminution technologies and devices are applied [8]. One of the new grinding devices is an electromagnetic mill, which, due to its grinding capabilities has a high potential for efficient comminution of raw materials at low energy costs. An important issue in application of electromagnetic mill is determination of the feed parameters which determines the efficiency of the mill's operation [4].
Feed preparation for beneficiation of fine-grained products (limestone meal, cement clinker) is a complex circuit of comminution (crushing, grinding) and classification (with recycle flows). Grinding is the basic operation, depending on the conditions and accepted technological assumptions, can take place in drum mills (eg rods, ball or cylpeps), Semi-Autogenous mills (SAG) and Autogenous ones (AG). In subsequent stages of grinding, vertical, vibratory, and other rotor mills are used. However, grinding the material (feed, ore) to a size below $0.1 \mathrm{~mm}$ is a very energy-intensive process. The amount of energy required for proper grinding depends primarily on the lithological composition of the raw material but also on the type of device $[1,2,3]$.

The grinding performance of the mill is determined by its work parameters, such as grinding time, roll speed, load, grinding media fulfilment, grinding media composition and size, physical and mechanical properties of the feed (particle size distribution, including maximum particle size and fine particles participation; susceptibility to crushing). By changing these parameters it is possible to reduce or increase the processing capacity of the mill. Properly selected parameters, taking into account their mutual impact on the efficiency of the operation of comminution equipment, are crucial in determination of the working conditions and can lead to improvement in the comminution process course and cost reduction $[1,2,3]$.

\footnotetext{
*Corresponding author: wolosiewiczm@gmail.com
} 


\section{Comminution technology in electromagnetic mill}

The electromagnetic mill is one of the devices, in which it is possible to achieve high technological efficiency of the process, measured by comminution ratio value, at maintaining high productivity and relatively low energy consumption.

Investigations in this field indicate that application of a circuit of simultaneous grinding and drying with the electromagnetic mill, offers the potential for achieving the desired fineness of the grinding product with favourable energy consumption ratios, as well as the ability to effectively control the process [5]. The electromagnetic mill is a device in which ferromagnetic grinding media are deliberately moved by a rotating electromagnetic field, which works as an energy carrier. The basic elements of the mill are: rotary magnetic field inductor and a tube in its axis, making the working chamber.

The working chamber is filled with ferromagnetic grinding media in approximately 20\%. They should be selected accordingly to the particle size of the feed [6,7]. In case of large material differentiation, a mixture of grinding media of different sizes is used. Possible changes in the size of the mills are connected to the physical properties of the feed and the final particle size distribution of grinding product.

The ability to control the feed-to-grinding media ratio, real-time particle size analysis and the operating condition of the mill, as well as flow volume of recycle allow for much more effective mechanical activation of the produced particles with strictly defined physicochemical parameters (size, shape, specific surface, surface properties). They also increase the grinding capacity and reduce the energy consumption $[6,7]$

Fig. 1. Electromagnetic field inductor (by D. Foszcz).

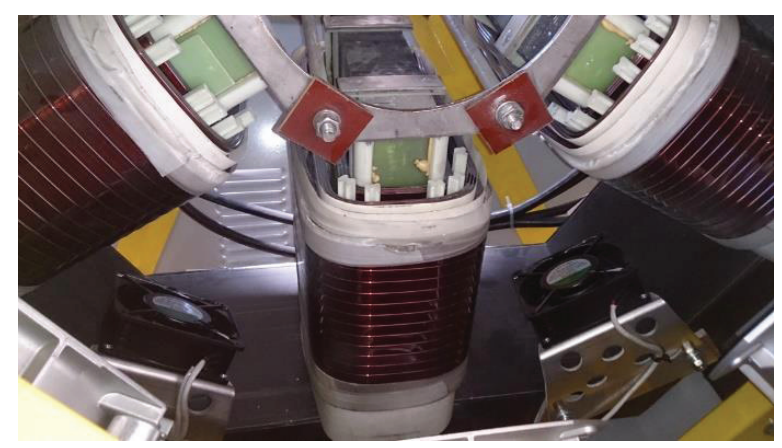

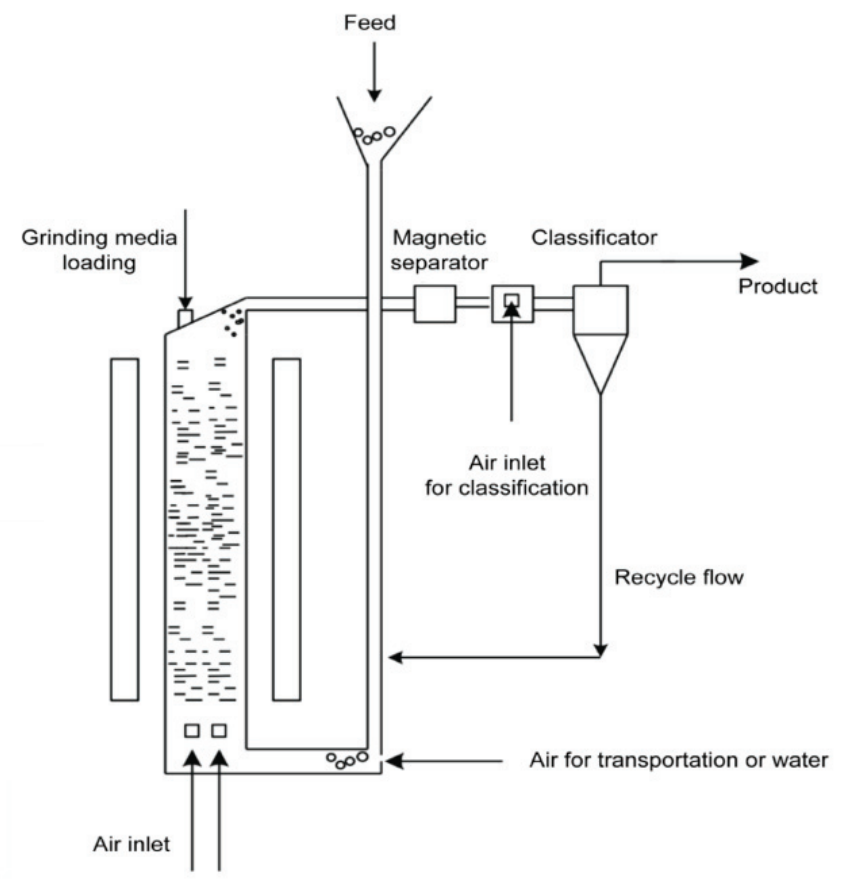

Fig. 2. Scheme of material flow through the electromagnetic mill [5].

The concept assumes the vertical position of the electromagnetic mill's working chamber, which is loaded from the bottom by screw feeder with the feed, and the stream of transport air, which is suitably moistened, is being provided [7]. Above the working chamber, there is a preliminary classifier integrated with a mill, which forms the inner recycle stream. The material is received from the working chamber of the mill from the top and goes to the pre-classifier. Course (not grinded) material returns along with the feed from the top to the working chamber and the material with suitable particle size is directed upwards towards the second (exact) classifier, which is designed as an inertial-impingement classifier. To ensure adequate transportation air flow speed and accurate classification, there is an adjustable additional air intake between the initial and the exact classifier. Exact classifier separates the stream of ground material to the end product and the recycle stream, providing the closed loop cycle of the mill operation [7]. 
However, due to the small size of the particles in recycle, to force the next passage through the working chamber, the recycle stream is fed from the bottom of the working chamber and its flow is controlled by a variable recycle air stream flow. The final product, coming out of the exact classifier, is separated from the transport air in the cyclone and goes to the final product tank. In addition, the installation is equipped with a cooling system of the working chamber in the form of a set of variable-capacity fans [7].

\section{Material and methods}

The experiments were carried out in a laboratory electromagnetic mill with a diameter of $200 \mathrm{~mm}$ - Fig. 3 . The feed consisted of copper ores with variable particle sizes $0-0.5 \mathrm{~mm}, 0-1 \mathrm{~mm}$ and $1-2 \mathrm{~mm}$.
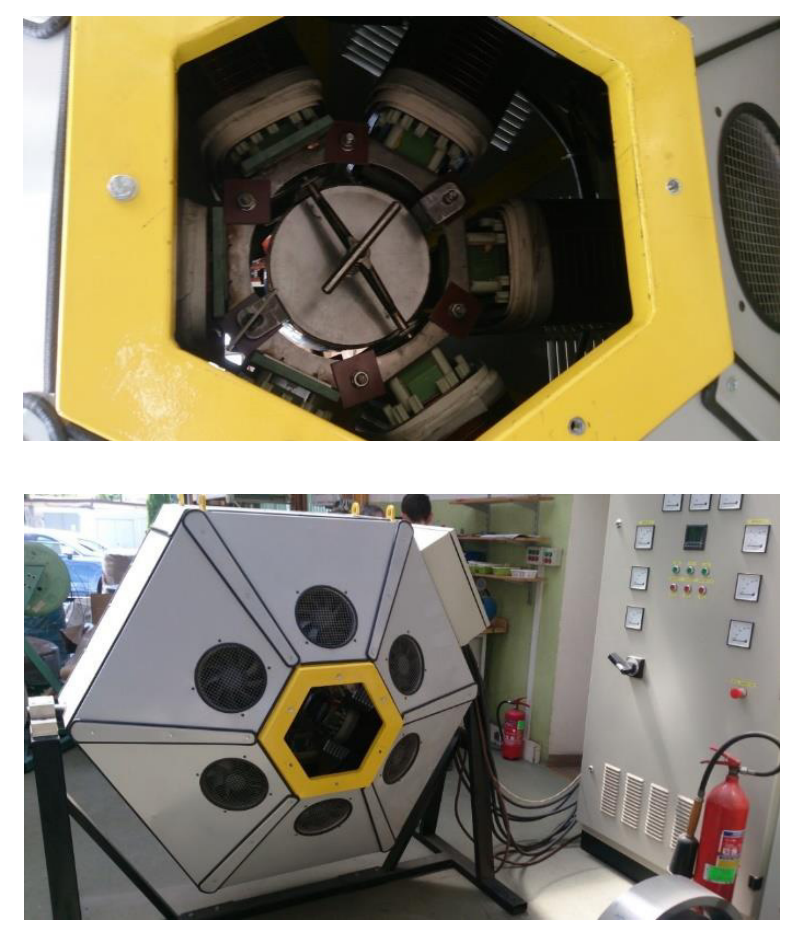

Fig. 3. Laboratory class electromagnetic mill with a diameter of $200 \mathrm{~mm}$ used for investigations (by D. Foszcz).
The tests involved the grinding of ore with three parameters of particle size distribution and four sets of grinding media of different sizes. Approximately 500 grams of material and 1500 grams of grinding media were used in each grinding test. Grinding times for the ore 0$0.5 \mathrm{~mm}$ and $0-1 \mathrm{~mm}$ were $5,10,15,20,25$ and 30 seconds; while for the ore 1-2 mm: 5, 10 and 20 seconds.

For each grinding product, the sieve analysis was performed and the increments of the analysed particle size classes $0-0,071 \mathrm{~mm}$ and $0-0,2 \mathrm{~mm}$ were determined.

The aim of the study was to evaluate the efficiency of the grinding process in an electromagnetic mill, depending on the size of the grinding media and the particle size distribution of the feed. The measure of effectiveness in this case was the yield of fine products - below $0.071 \mathrm{~mm}$ and $0-0.2 \mathrm{~mm}$. The objective of the research was to try to select the appropriate size of the grinding media in order to obtain optimum technological results in the fine particles yield and the obtained fineness in grinding products for variable particle size distribution of the feed.

\section{Results of investigations}

The obtained particle size of the ore from the electromagnetic mill milling products is shown in Tables 1-3.



Fig. 4. Material and grinding media after grinding in electromagnetic mill [by M. Wołosiewicz-Głąb).

Table 1. Particle size distribution of the ore grinding products in the electromagnetic mill for the feed size 1-2 mm.

\begin{tabular}{|c|c|c|c|c|c|c|c|c|c|c|c|c|c|c|c|c|}
\hline \multirow{3}{*}{$\underset{[\mathrm{mm}]}{\mathbf{d}}$} & \multicolumn{4}{|c|}{ Grinding media 10/1 } & \multicolumn{4}{|c|}{ Grinding media 12/1,5 } & \multicolumn{4}{|c|}{ Grinding media 12/2 } & \multicolumn{4}{|c|}{ Mixture of grinding media } \\
\hline & Feed & $\begin{array}{l}t=5 \\
\sec \end{array}$ & $\begin{array}{l}t=10 \\
\text { sec }\end{array}$ & $\begin{array}{c}t=20 \\
\text { sec }\end{array}$ & Feed & $\begin{array}{l}t=5 \\
\text { sec }\end{array}$ & $\begin{array}{l}t=10 \\
\text { sec }\end{array}$ & $\begin{array}{c}t=20 \\
\text { sec }\end{array}$ & Feed & $\begin{array}{l}t=5 \\
\text { sec }\end{array}$ & $\begin{array}{l}t=10 \\
\text { sec }\end{array}$ & $\begin{array}{c}t=20 \\
\text { sec }\end{array}$ & Feed & $\begin{array}{l}t=5 \\
\text { sec }\end{array}$ & $\begin{array}{l}t=10 \\
\text { sec }\end{array}$ & $\begin{array}{c}t=20 \\
\text { sec }\end{array}$ \\
\hline & $\begin{array}{l}\phi(d) \\
{[\%]}\end{array}$ & $\begin{array}{l}(\mathrm{d}) \\
{[\%]}\end{array}$ & $\begin{array}{l}\phi(d) \\
{[\%]}\end{array}$ & $\begin{array}{l}\phi(d) \\
{[\%]}\end{array}$ & $\begin{array}{l}\phi(d) \\
{[\%]}\end{array}$ & $\begin{array}{l}(d) \\
{[\%]}\end{array}$ & $\begin{array}{l}\phi(d) \\
{[\%]}\end{array}$ & $\begin{array}{l}\phi(d) \\
{[\%]}\end{array}$ & $\begin{array}{l}\phi(d) \\
{[\%]}\end{array}$ & $\begin{array}{l}\phi(d) \\
{[\%]}\end{array}$ & $\begin{array}{l}\phi(d) \\
{[\%]}\end{array}$ & $\begin{array}{l}\phi(d) \\
{[\%]}\end{array}$ & $\begin{array}{l}\phi(d) \\
{[\%]}\end{array}$ & $\begin{array}{l}\phi(d) \\
{[\%]}\end{array}$ & $\begin{array}{l}\phi(d) \\
{[\%]}\end{array}$ & $\begin{array}{l}\phi(d) \\
{[\%]}\end{array}$ \\
\hline 0 & 0 & 0 & 0 & 0 & 0 & 0 & 0 & 0 & 0 & 0 & 0 & 0 & 0 & 0 & 0 & 0 \\
\hline 0.071 & 0 & 20.3 & 31.6 & 46.1 & 0 & 16.7 & 35.0 & 54.6 & 0 & 17.1 & 33.2 & 56.1 & 0 & 20.5 & 39.9 & 53.3 \\
\hline 0.16 & 0 & 22.5 & 33.7 & 48.1 & 0 & 21.2 & 40.0 & 59.7 & 0 & 21.5 & 39.0 & 64.6 & 0 & 24.3 & 43.6 & 59.2 \\
\hline 0.2 & 0 & 23.3 & 34.5 & 48.7 & 0 & 22.4 & 41.7 & 61.1 & 0 & 23.3 & 41.5 & 67.1 & 0 & 25.6 & 45.2 & 60.4 \\
\hline 0.4 & 0 & 26.4 & 37.3 & 50.6 & 0 & 27.6 & 48.2 & 65.5 & 0 & 29.9 & 50.5 & 74.2 & 0 & 30.5 & 50.0 & 64.0 \\
\hline 0.63 & 0 & 29.3 & 40.4 & 52.7 & 0 & 33.5 & 54.2 & 68.7 & 0 & 36.8 & 59.0 & 78.9 & 0 & 35.9 & 55.5 & 67.3 \\
\hline 1 & 0 & 39.9 & 48.8 & 58.5 & 0 & 44.3 & 64.2 & 75.3 & 0 & 50.3 & 69.9 & 83.9 & 0 & 47.4 & 62.9 & 73.1 \\
\hline 2 & 100 & 100 & 100 & 100 & 100 & 100 & 100 & 100 & 100 & 100 & 100 & 100 & 100 & 100 & 100 & 100 \\
\hline
\end{tabular}


Table 2. Particle size distribution of the ore grinding products in the electromagnetic mill for the feed size $0-1 \mathrm{~mm}$.

\begin{tabular}{|c|c|c|c|c|c|c|c|c|c|c|c|c|c|c|}
\hline \multirow{3}{*}{$\underset{[\mathrm{mm}]}{\mathbf{d}}$} & \multicolumn{7}{|c|}{ Grinding media 10/1 } & \multicolumn{7}{|c|}{ Grinding media 12/1,5 } \\
\hline & Feed & $t=5 \mathrm{sec}$ & $\begin{array}{c}\mathrm{t}=10 \\
\text { sec }\end{array}$ & $\begin{array}{c}t=15 \\
\text { sec }\end{array}$ & $\begin{array}{c}\mathrm{t}=20 \\
\text { sec }\end{array}$ & $\begin{array}{c}\mathrm{t}=25 \\
\text { sec }\end{array}$ & $\begin{array}{c}\mathbf{t}=30 \\
\text { sec }\end{array}$ & Feed & $\mathrm{t}=5 \mathrm{sec}$ & $\begin{array}{c}\mathbf{t}=10 \\
\text { sec }\end{array}$ & $\begin{array}{c}\mathrm{t}=15 \\
\mathrm{sec}\end{array}$ & $\begin{array}{c}\mathbf{t}=\mathbf{2 0} \\
\mathrm{sec}\end{array}$ & $\begin{array}{c}t=25 \\
\text { sec }\end{array}$ & $\begin{array}{c}\mathbf{t}=\mathbf{3 0} \\
\text { sec }\end{array}$ \\
\hline & $\begin{array}{l}\phi(d) \\
{[\%]} \\
\end{array}$ & $\begin{array}{l}\phi(d) \\
{[\%]}\end{array}$ & $\begin{array}{l}\phi(d) \\
{[\%]}\end{array}$ & $\begin{array}{l}\phi(d) \\
{[\%]}\end{array}$ & $\begin{array}{l}\phi(d) \\
{[\%]}\end{array}$ & $\begin{array}{l}\phi(d) \\
{[\%]}\end{array}$ & $\begin{array}{l}\phi(d) \\
{[\%]}\end{array}$ & $\begin{array}{l}\phi(d) \\
{[\%]}\end{array}$ & $\begin{array}{l}\phi(d) \\
{[\%]}\end{array}$ & $\begin{array}{l}\phi(d) \\
{[\%]}\end{array}$ & $\begin{array}{l}\phi(d) \\
{[\%]}\end{array}$ & $\begin{array}{l}\phi(d) \\
{[\%]}\end{array}$ & $\begin{array}{l}\phi(d) \\
{[\%]}\end{array}$ & $\begin{array}{l}\phi(d) \\
{[\%]}\end{array}$ \\
\hline 0 & 0 & 0 & 0 & 0 & 0 & 0 & 0 & 0 & 0 & 0 & 0 & 0 & 0 & 0 \\
\hline 0.071 & 52.5 & 83.5 & 96.2 & 99.8 & 100.0 & 100.0 & 100.0 & 54.9 & 77.0 & 81.5 & 95.5 & 99.5 & 99.9 & 100.0 \\
\hline 0.12 & 58.0 & 88.1 & 98.8 & 100.0 & 100.0 & 100.0 & 100.0 & 59.3 & 82.5 & 88.4 & 99.8 & 100.0 & 100.0 & 100.0 \\
\hline 0.2 & 64.1 & 94.5 & 99.9 & 100.0 & 100.0 & 100.0 & 100.0 & 67.4 & 89.2 & 95.2 & 100.0 & 100.0 & 100.0 & 100.0 \\
\hline 0.4 & 80.2 & 100.0 & 100.0 & 100.0 & 100.0 & 100.0 & 100.0 & 97.8 & 99.4 & 100.0 & 100.0 & 100.0 & 100.0 & 100.0 \\
\hline 0.63 & 96.8 & 100.0 & 100.0 & 100.0 & 100.0 & 100.0 & 100.0 & 100.0 & 100.0 & 100.0 & 100.0 & 100.0 & 100.0 & 100.0 \\
\hline 1 & 100.0 & 100.0 & 100.0 & 100.0 & 100.0 & 100.0 & 100.0 & 100.0 & 100.0 & 100.0 & 100.0 & 100.0 & 100.0 & 100.0 \\
\hline \multirow{3}{*}{$\underset{[\mathrm{mm}]}{\mathbf{d}}$} & \multicolumn{7}{|c|}{ Grinding media 12/2 } & \multicolumn{7}{|c|}{ Mixture of grinding media } \\
\hline & Feed & $\mathrm{t}=5 \mathrm{sec}$ & $\begin{array}{c}\mathbf{t}=10 \\
\text { sec }\end{array}$ & $\begin{array}{c}\mathbf{t}=15 \\
\text { sec }\end{array}$ & $\begin{array}{c}\mathbf{t}=20 \\
\text { sec }\end{array}$ & $\begin{array}{c}\mathrm{t}=25 \\
\mathrm{sec}\end{array}$ & $\begin{array}{c}\mathrm{t}=30 \\
\mathrm{sec}\end{array}$ & Feed & $\mathrm{t}=5 \mathrm{sec}$ & $\begin{array}{c}\mathrm{t}=10 \\
\mathrm{sec}\end{array}$ & $\begin{array}{c}t=15 \\
\text { sec }\end{array}$ & $\begin{array}{c}\mathbf{t}=\mathbf{2 0} \\
\mathrm{sec}\end{array}$ & $\begin{array}{l}t=25 \\
\text { sec }\end{array}$ & $\begin{array}{c}\mathbf{t}=\mathbf{3 0} \\
\mathrm{sec}\end{array}$ \\
\hline & $\begin{array}{l}\phi(d) \\
{[\%]}\end{array}$ & $\begin{array}{l}\phi(d) \\
{[\%]}\end{array}$ & $\begin{array}{l}\phi(d) \\
{[\%]}\end{array}$ & $\begin{array}{l}\phi(d) \\
{[\%]}\end{array}$ & $\begin{array}{l}\phi(d) \\
{[\%]}\end{array}$ & $\begin{array}{l}\phi(d) \\
{[\%]}\end{array}$ & $\begin{array}{l}\phi(d) \\
{[\%]}\end{array}$ & $\begin{array}{l}\phi(d) \\
{[\%]}\end{array}$ & $\begin{array}{l}\phi(d) \\
{[\%]}\end{array}$ & $\begin{array}{l}\phi(d) \\
{[\%]}\end{array}$ & $\begin{array}{l}\phi(d) \\
{[\%]}\end{array}$ & $\begin{array}{l}\phi(d) \\
{[\%]}\end{array}$ & $\begin{array}{l}\phi(d) \\
{[\%]}\end{array}$ & $\begin{array}{l}\phi(d) \\
{[\%]}\end{array}$ \\
\hline 0 & 0 & 0 & 0 & 0 & 0 & 0 & 0 & 0 & 0 & 0 & 0 & 0 & 0 & 0 \\
\hline 0.071 & 54.9 & 67.3 & 77.5 & 94.2 & 98.8 & 99.5 & 99.5 & 54.9 & 79.2 & 88.5 & 98.5 & 99.9 & 100.0 & 100.0 \\
\hline 0.12 & 59.3 & 73.3 & 84.2 & 98.8 & 100.0 & 100.0 & 100.0 & 59.3 & 84.2 & 94.9 & 100.0 & 100.0 & 100.0 & 100.0 \\
\hline 0.2 & 67.4 & 82.0 & 91.8 & 99.9 & 100.0 & 100.0 & 100.0 & 67.4 & 91.5 & 99.3 & 100.0 & 100.0 & 100.0 & 100.0 \\
\hline 0.4 & 97.8 & 99.1 & 99.8 & 100.0 & 100.0 & 100.0 & 100.0 & 97.8 & 99.7 & 100.0 & 100.0 & 100.0 & 100.0 & 100.0 \\
\hline 0.63 & 100.0 & 100.0 & 100.0 & 100.0 & 100.0 & 100.0 & 100.0 & 100.0 & 100.0 & 100.0 & 100.0 & 100.0 & 100.0 & 100.0 \\
\hline 1 & 100.0 & 100.0 & 100.0 & 100.0 & 100.0 & 100.0 & 100.0 & 100.0 & 100.0 & 100.0 & 100.0 & 100.0 & 100.0 & 100.0 \\
\hline
\end{tabular}

Table 3. Particle size distribution of the ore grinding products in the electromagnetic mill for the feed size $0-0,5 \mathrm{~mm}$.

\begin{tabular}{|c|c|c|c|c|c|c|c|}
\hline \multirow{3}{*}{$\underset{[\mathrm{mm}]}{\mathbf{d}}$} & \multicolumn{7}{|c|}{ Grinding media 10/1 } \\
\hline & Feed & $t=5 \mathrm{sec}$ & $\begin{array}{c}t=10 \\
\text { sec }\end{array}$ & $\begin{array}{c}\mathrm{t}=15 \\
\mathrm{sec}\end{array}$ & $\begin{array}{c}\mathrm{t}=20 \\
\mathrm{sec}\end{array}$ & $\begin{array}{c}t=25 \\
\text { sec }\end{array}$ & $\begin{array}{c}\mathbf{t}=\mathbf{3 0} \\
\text { sec }\end{array}$ \\
\hline & $\begin{array}{l}\phi(d) \\
{[\%]}\end{array}$ & $\begin{array}{l}\phi(\mathbf{d}) \\
{[\%]}\end{array}$ & $\begin{array}{l}\phi(d) \\
{[\%]}\end{array}$ & $\begin{array}{l}\phi(d) \\
{[\%]}\end{array}$ & $\begin{array}{l}\phi(d) \\
{[\%]}\end{array}$ & $\begin{array}{l}\phi(d) \\
{[\%]}\end{array}$ & $\begin{array}{l}\phi(d) \\
{[\%]}\end{array}$ \\
\hline 0 & 60.1 & 89.9 & 98.6 & 99.9 & 100.0 & 100.0 & 100.0 \\
\hline 0,071 & 66.1 & 95.8 & 100.0 & 100.0 & 100.0 & 100.0 & 100.0 \\
\hline 0,16 & 75.7 & 99.1 & 100.0 & 100.0 & 100.0 & 100.0 & 100.0 \\
\hline 0,2 & 97.6 & 100.0 & 100.0 & 100.0 & 100.0 & 100.0 & 100.0 \\
\hline 0,4 & 100.0 & 100.0 & 100.0 & 100.0 & 100.0 & 100.0 & 100.0 \\
\hline 0,63 & 100.0 & 100.0 & 100.0 & 100.0 & 100.0 & 100.0 & 100.0 \\
\hline 1 & 60.1 & 89.9 & 98.6 & 99.9 & 100.0 & 100.0 & 100.0 \\
\hline 2 & 66.1 & 95.8 & 100.0 & 100.0 & 100.0 & 100.0 & 100.0 \\
\hline
\end{tabular}

In order to evaluate the grinding efficiency of the electromagnetic mill for the analysed variable sizes of grinding media and particle size distribution, the increments of the size fraction $0-0.071 \mathrm{~mm}$ and $0-0.2 \mathrm{~mm}$ were calculated. The results are shown in Figures 5-7.

The results of ore grinding in the electromagnetic mill confirmed the high efficiency of this device in the process of ore comminution - the expected fineness was reached after about 10-15 seconds. Analysis of selected particle size fractions indicates that for fine grained feed with particle size less than $1 \mathrm{~mm}$, the most suitable choice of grinding media are the ones with dimensions $10 / 1 \mathrm{~mm}$ or a mixture of grinding media. For feed with particle size 1$2 \mathrm{~mm}$, the $0-0.071 \mathrm{~mm}$ particle size fraction increment for individual grinding media sizes and mixtures was not so unequivocal and depends on the grinding time. For 5 seconds time the most advantageous for obtaining a high increment of this particle size fraction are $10 / 1 \mathrm{~mm}$ grinding media. In case of $0-0,200 \mathrm{~mm}$ particle size fraction, the most suitable were the ones with $12 / 2 \mathrm{~mm}$ dimension. The high efficiency of grinding in the electromagnetic mill causes that some of the increments of the analysed particle size fractions reach a maximum value of $100 \%$ after $5-15$ seconds. This implies the need to control the process in terms of material residence time in working chamber because further grinding results in material fineness below the expected dimension, which is undesirable.

The obtained results indicate the need for optimization of the size of the grinding media or their mixtures, as well as the grinding time depending on the particle size distribution of the feed in order to obtain the desired product characteristics. It is particularly important to determine the residence time of the material in the mill in the context of product comminution and operating costs requirements. 




a)

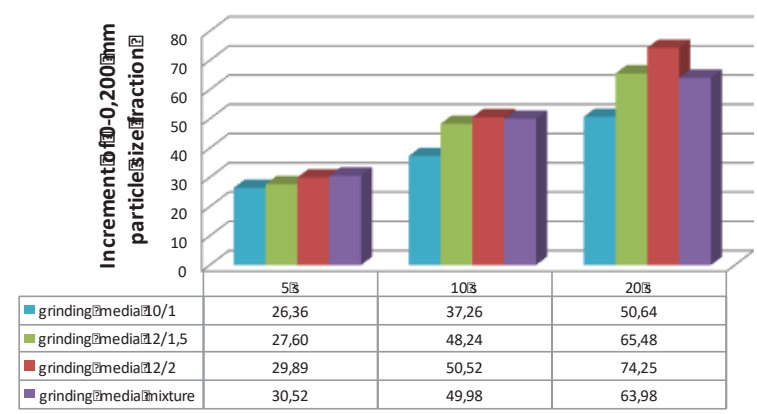

b)

Fig. 5. Increment of $0-0,071 \mathrm{~mm}$ and $0-0,2 \mathrm{~mm}$ particle size fraction during grinding in electromagnetic grinding mill for the feed particle size $1-2 \mathrm{~mm}$.

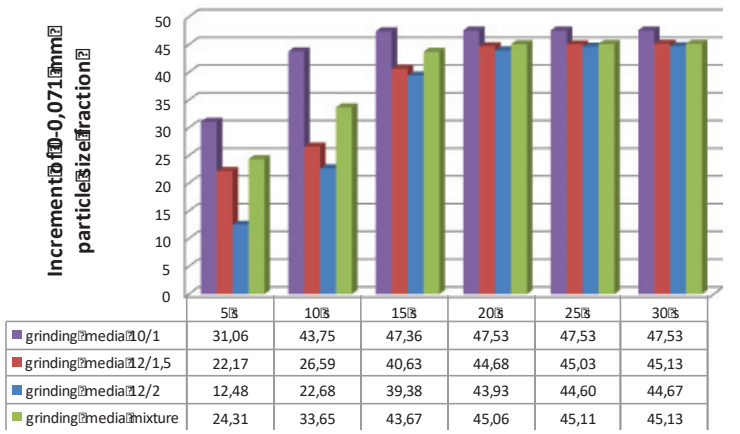

a)

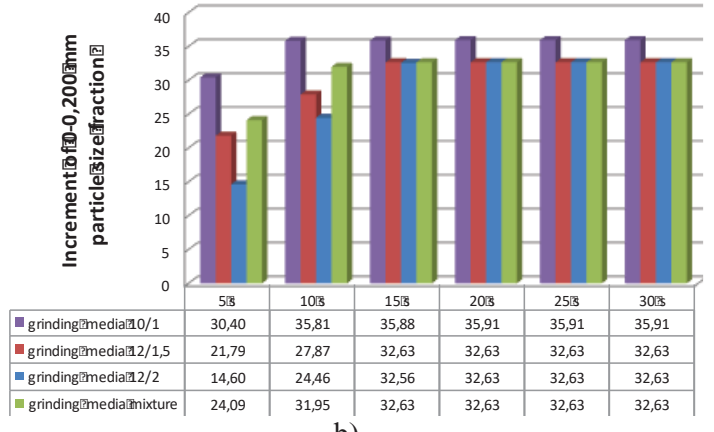

b)

Fig. 6. Increment of 0-0,071 $\mathrm{mm}$ and $0-0,2 \mathrm{~mm}$ particle size fraction during grinding in electromagnetic grinding mill for the feed particle size $0-1 \mathrm{~mm}$.

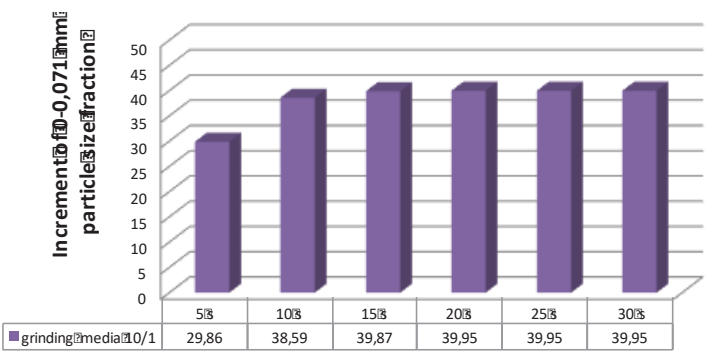

a)

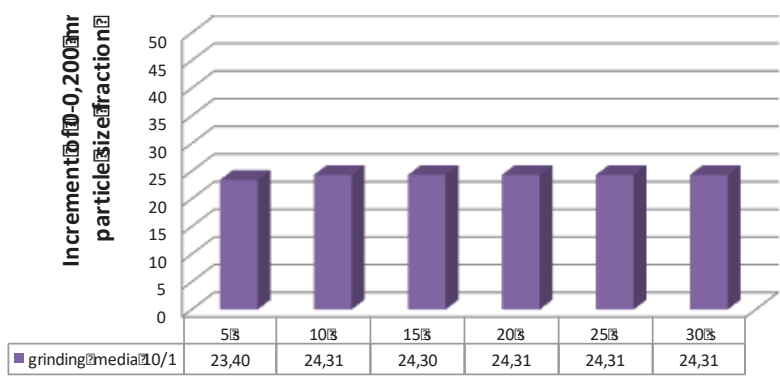

b)

Fig. 7. Increment of 0-0,071 $\mathrm{mm}$ and $0-0,2 \mathrm{~mm}$ particle size fraction during grinding in electromagnetic grinding mill for the feed particle size $0-0,5 \mathrm{~mm}$.

\section{Conclusions}

Proper selection of equipment according to feed parameters is crucial in achieving the intended aims of the grinding process. Grinding circuit based on electromagnetic mill offers great opportunities for the process, comminution performance and control of product parameters. The research shows possibilities of additional control of the particle size of products by changing the grinding time and the size of the grinding media. The results of the investigations presented in the article indicate that small grinding media should be used for grinding of fine feed. For feed with particle size less than $1 \mathrm{~mm}$, grinding media should not be greater than $1 \times 10$ $\mathrm{mm}$.

The tests carried out in this article have been conducted in a laboratory unit with periodic operation and should not be directly translated into an industrial size installation. The device described in this article will allow for a more complex control of the grinding process in order to obtain a product with specific parameters.

The article has been written within the framework of the project: PBS3/B3/28/2015.

\section{References}

1. D. Foszcz, T. Gawenda, AGH Journal of Mining and Geoingineering, (AGH University of Science and Technology Press, 36, 2012)

2. D. Saramak, T. Tumidajski, B. Brożek, T. Gawenda, Z. Naziemiec, Gospodarka Surowcami Mineralnymi Polska Akademia Nauk, 26 (2010) 
3. T. Tumidajski, E. Kasińska-Pilut, T. Gawenda, Z. Naziemiec, R. Pilut, Gospodarka Surowcami Mineralnymi, Polska Akademia Nauk, 26 (2010)

4. T. Gawenda, Monograph No. 304 (Wydawnictwo AGH, 2015)

5. M. Wołosiewicz-Głąb, D. Foszcz, T. Gawenda, Mineral Engineering Conference, (Szczwanica, 212227, 2016)
6. M. Wołosiewicz-Głąb, Sz. Ogonowski, D. Foszcz, IFAC Symposium On Control, Optimization And Automation In Mining, Mineral And Metal Processing (Vienna, Austria, 2016)

7. Sz. Ogonowski, Z. Ogonowski, M. Pawełczyk, $21^{\text {st }}$ International Conference MMAR (2016)

8. D. Saramak, Gospodarka Surowcami Mineralnymi Mineral Resources Management, 28, 4 (2012) 